Please quote as: Schöbel, S.; Janson, A.; Hopp, J. C. \& Leimeister, J. M. (2019): Gamification of Online Training and its Relation to Engagement and Problem-solving Outcomes. In: Academy of Management Annual Meeting (AOM). Boston, Massachusetts, USA. 


\title{
Gamification of Online Training and its Relation to Engagement and Problem-solving Out- comes
}

\author{
Authors \\ Sofia Schöbel ${ }^{1}$, Andreas Janson ${ }^{1}$, Hopp, Jennifer Christin ${ }^{1}$, Jan Marco Leimeister ${ }^{1,2}$ \\ ${ }^{1}$ University of Kassel \\ Information Systems, Research Center for IS Design (ITeG) \\ E-Mail: sofia.schoebel@uni-kassel.de, andreas.janson@uni-kassel.de, hopp@wi-kassel.de, lei- \\ meister@uni-kassel.de \\ ${ }^{2}$ University of St. Gallen \\ Institute of Information Management \\ E-Mail: leimeister@unisg.ch
}

\begin{abstract}
Online training to teach students problem-solving skills is becoming increasingly important. However, due to the complexity of such training, it is challenging to keep learners motivated and engaged in the learning process. One concept that can be used to motivate and engage learners is gamification. Gamification is about using game elements in non-game contexts. Research is lacking on which determinants of gamification promote engagement and improve problem-solving outcomes in learning. Therefore, the goal of our study is to analyze how gamification can impact engagement, problem solving outcomes and their related constructs such as motivation in IT-based training. To achieve our goal, we conducted a randomized experiment by creating a gamified online training program to teach students how to construct and develop value proposition canvases. The results of our study indicate that engagement is a central construct for explaining the effects of gamification on problem-solving outcomes. Our results contribute to theory by explaining the meaning and role of motivation, engagement, and their influence on the problem-solving skills learned by the students. We contribute to practice by offering suggestions regarding the design of online training programs and how to make them more motivating and engaging to learners.
\end{abstract}

\section{Keywords:}

Gamification, Learning, Learner Motivation, Engagement, Problem-solving Skills, Extrinsic Motivation, Intrinsic Motivation, Game Elements 